\title{
HIGH PERFORMANCE LIQUID CHROMATOGRAPHY FOR DETERMINATION OF METOPROLOL ENANTIOMERS IN PHARMACEUTICAL FORMULATIONS
}

\author{
Sylwia Magiera*, Weronika Adolf, Irena Baranowska \\ Department of Inorganic, Analytical Chemistry and Electrochemistry, \\ Silesian University of Technology, \\ 7 M. Strzody Str., 44-100 Gliwice, Poland \\ E-mail: sylwia.magiera@polsl.pl
}

\begin{abstract}
A novel high performance liquid chromatography with fluorescence detector (HPLC-FL) method for determination of metoprolol enantiomers in a pharmaceutical formulation was developed and validated. This study investigated the ultrasound-assisted extraction (UAE) of metoprolol from commercial tablets using methanol as extraction solvent. The separation of enantiomers was successfully carried out with a CHIRALCEL OD-RH column, under isocratic elution mode using $0.05 \%$ trifluoroacetic acid and $0.05 \%$ diethylamine in water and acetonitrile $(80: 20, \mathrm{v} / \mathrm{v})$.
\end{abstract}

The chromatographic method was validated in terms of precision, accuracy, detection and quantification limits, linearity and recovery. Calibration curves were linear in the investigated range with correlation coefficient better than 0.9931 while the limit of quantifications was $0.19 \mu \mathrm{g} \mathrm{mL}^{-1}$ for $S(-)$-MET and $0.23 \mu \mathrm{g} \mathrm{mL}^{-1}$ for $R(+)$-MET. The mean recovery of $S(-)$-MET and $R(+)$-MET from tablets were found to be $78.8 \%$ and $92.1 \%$, respectively.

This method for the direct determination and quantification of metoprolol enantiomers in pharmaceutical formulations is suitable for routine analyses in quality control laboratories and was applied to evaluate for the first time, the presence and the quantities of cited analytes in commercially available formulation.

\section{Indexing terms/Keywords}

Metoprolol; enantiomers; chiral separation; pharmaceutical formulations.

\section{Academic Discipline And Sub-Disciplines}

Analytical Chemistry

\section{SUBJECT CLASSIFICATION}

Chemistry

\section{TYPE (METHOD/APPROACH)}

\section{Experimental}

\section{Council for Innovative Research}

Peer Review Research Publishing System

Journal: Journal of Advances in Chemistry

Vol. 10, No. 4

editorjaconline@gmail.com 


\section{INTRODUCTION}

Metoprolol (MET) is a $\beta_{1}$ selective aryloxypropanol amine adrenergic antagonist used extensively in the treatment of a variety of cardiovascular disorders. The structures of metoprolol were presented on Figure 1 . The pharmaceutical products containing metoprolol are marketed as a racemic mixture of $S(-)$-MET and $R(+)$-MET and metoprolol is administered as a racemic mixture. (S)-(-)-metoprolol has been reported to be significantly greater $\beta_{1}$ adrenergic receptor affinity by $>25$-fold than $(R)-(+)$-metoprolol [1]. The great difference in pharmacological effect and pharmacokinetics between the two enantiomeric forms has needed methods for enantioselective separation and determination in pharmaceutical formulations.<smiles>COCCc1ccc(OC[C@@H](O)CNC(C)C)cc1</smiles>

Figure 1. Chemical structure of metoprolol.

Metoprolol enantioseparation has previously been performed with the aid of capillary electrophoresis with the use of cyclodextrines as chiral selectors [2] as well as liquid chromatography [1,3-9] with the use of derivatization of metoprolol [3] or chiral stationary phases [4-11]. The most frequently method of detection metoprolol enantiomers is fluorescence detection [1,3-6], UV detection [2,7], and MS/MS [8,9]. Up to now, metoprolol enantiomers was determined only in water [8], human blood, plasma and urine samples [1-7,9] and in tablet preparations [10,11].

In the present paper the new method for chromatographic separation and quantification of metoprolol enantiomers on chiral cellulose tris(3,5-dimethylphenylcarbamate) stationary phase, was described. The new procedure was successfully applied for the determination of metoprolol in medicinal products.

\section{EXPERIMENTAL}

\subsection{Chemicals and reagents}

$S(-)$-metoprolol $(S(-)-\mathrm{MET})$ and $R(+)$-metoprolol $(R(+)-\mathrm{MET})$ enantiomers ( $\geq 99 \%$ purity) were purchased from Toronto Research Chemicals Inc. (North York, Canada). HPLC-grade acetonitrile (ACN), water, diethylamine (DEA), trifluoroacetic acid (TFA) were purchased from Merck (Darmstadt, Germany). Analytical grade methanol were purchased from POCH S.A. (Gliwice, Poland).

\subsection{Preparation of stock solutions, calibration standards and quality control (QC) solutions}

Standard stock solutions of metoprolol enentiomers were prepared in methanol at a concentration of $1 \mathrm{mg} \mathrm{mL}^{-1}$. A series of working solutions containing analytes were prepared in methanol by diluting appropriate amounts of the standard stock solutions to concentration levels among the range of $0.5-10.0 \mu \mathrm{g} \mathrm{mL}^{-1}$ for analysed compounds. All working solutions were stored at $4^{\circ} \mathrm{C}$ and brought to room.

Calibration standards (CS) solutions of MET enantiomers were prepared by dilution of the working standards with methanol in the concentration range $0.25-1.50 \mu \mathrm{g} \mathrm{mL}^{-1}$.

Quality control $(\mathrm{QC})$ samples were similarly prepared at three concentration levels: the low concentration of quality control (LQC), $0.25 \mu \mathrm{g} \mathrm{mL}^{-1}$, medium concentration quality control (MQC), $0.75 \mu \mathrm{g} \mathrm{mL}^{-1}$ and high concentration quality control (HQC) $1.50 \mu \mathrm{g} \mathrm{mL}^{-1}$.

\subsection{Instrumentation and UHPLC-UV analytical conditions}

HPLC analyses were performed on a Merck Hitachi liquid chromatograph equipped with a Model L-6200A Inteligent Pump with a dynamic mixer chamber, Model L-4500A, a Model L-7480 photodiode array detector (DAD), and a Model L-7360 fluorescence detector (FL).

An CHIRALCEL OD-RH $(150 \times 4.6 \mathrm{~mm}, 5 \mu \mathrm{m})$ column (Daicel/Chiral Technologies, Illkirch, France) equipped with a CHIRALCEL OD-RH analytical guard column was employed for the separation of metoprolol enantiomers. The mobile phase consisted of a mixture of $0.05 \%$ trifluoroacetic acid (TFA) and $0.05 \%$ diethylamine (DEA) in water:acetonitrile $(80: 20, \mathrm{v} / \mathrm{v})$. The flow rate was set at $1.0 \mathrm{~mL} \mathrm{~min}^{-1}$ and resulted in a total run time of $30 \mathrm{~min}$. The samples were injected using Rheodyne valve with a $20 \mu \mathrm{L}$ loop.

For quantitative analyses, selective detection was performed at $225 \mathrm{~nm}$ as an excitation wavelength and at $310 \mathrm{~nm}$ as an emission wavelength. 


\subsection{Sample preparation}

Three tablets, each one containing $50 \mathrm{mg}$ of metoprolol, were weighed, their mean weight determined and they were ground to a fine powder using a glass mortar and pestle. An equivalent of $50 \mathrm{mg}$ active ingredient drug was accurately weighed and diluted in $50 \mathrm{~mL}$ methanol. The mixture was shaken for $60 \mathrm{~min}$, treated with ultrasound for 20 min at room temperature and then filtrated. Next sample was transferred into a $100 \mathrm{~mL}$ volumetric flask and made up to volume with methanol. For assay, the tablet solution was diluted 1:20 (v/v) with methanol. With this solution, further dilution 1:20 (v/v) was done and $20 \mu \mathrm{L}$ solution was injected three times directly onto the HPLC column.

\subsection{Method validation}

The linearity of the proposed method was evaluated by using calibration curves to calculate coefficient of determination and intercept values. Calibration curves were calculated, in triplicate, by analyzing calibration standard solutions prepared each day at five concentration levels. The concentration range for all the enantiomers was $0.25-1.5 \mu \mathrm{g} \mathrm{m}^{-1}$. Calibration graphs were obtained by plotting the peak areas of the analytes versus the corresponding analyte concentrations.

The limit of detection (LOD) and limit of quantification (LOQ) were calculated according to ICH Q2R1 recommendations using the following equation [12]:

\section{$L O D=3.3 \cdot S_{a} / b$ and $L O Q=3 \cdot L O D$}

where $S_{a}$ - the standard deviation of the intercept of the calibration curve, and $b$ - the slope of the calibration curve.

Intra-day precision and accuracy of the proposed methods were evaluated by assaying freshly prepared solutions in triplicates at three different concentrations of metoprolol enantiomers $\left(0.25,0.75,1.50 \mu \mathrm{g} \mathrm{mL} \mathrm{L}^{-1}\right)$. Inter-day precision and accuracy of the proposed methods were evaluated by assaying freshly prepared solutions in triplicates for three consecutive days. The precision was estimated as the relative standard deviation (RSD) for each QC sample, which was calculated by dividing the standard deviation (SD) of the measured concentrations by the mean concentration: $\operatorname{RSD}(\%)=\left(S D / C_{\text {mean,mes }}\right) \times 100$. The accuracy was defined as the difference between the measured $\left(C_{\text {mes }}\right)$ and nominal $\left(\mathrm{C}_{\text {nom }}\right)$ concentrations of the low $\mathrm{QC}$, medium $\mathrm{QC}$ samples and high QC samples and was expressed as the relative error: $\operatorname{RE}(\%)=\left[\left(\mathrm{C}_{\mathrm{mes}}-\mathrm{C}_{\mathrm{nom}}\right) / \mathrm{C}_{\mathrm{nom}}\right] \times 100$.

A recovery test was carried out on three different concentration levels of the reference standards $(0.25,0.75$, $1.50 \mathrm{~m} \mathrm{~mL}^{-1}$ ), which were added to a powdered sample of the tablet dosage form without metoprolol. The solutions were extracted and quantified as described before.

\section{RESULTS AND DISCUSSION}

\subsection{Method development}

The aim of the present study was to develop a simple, isocratic, accurate and sensitive HPLC method for determination of $S(-)$-MET and $R(+)$-MET in pharmaceutical dosage forms. Preliminary tests were performed with the objective to select chromatographic and detection conditions. Parameters, such as detection wavelength, mobile phase and their proportions, optimum $\mathrm{pH}$ and stationery phases were studied. Several binary or ternary eluents were tested using different proportions of solvents, such as acetonitrile, methanol and water with addition of trifluoroacetic acid, acetic acid, formic acid and ammonium hydroxide, diethylamine and triethyloamie. The analytes chromatographic behavior was investigated by means of different HPLC stationary phase packaging as well as Lux Amylose-2 (amylose tris(5-chloro-2methylphenylcarbamate)), Lux Cellulose-1 (cellulose tris(3,5-dimethylphenyl-carbamate), and Lux Cellulose-3 (cellulose tris(4-methylbenzoate)

The mobile phase consisting of $0.05 \%$ TFA and $0.05 \%$ DEA in water and acetonitrile in the ratio of $(80: 20$, v/v) was found appropriate for separation of both the enantiomers using a CHIRALCEL ${ }^{\circledR}$ OD-RH column with cellulose tris-(3,5dimethylphenylcarbamate) as the packing material. The mobile phase was modified with two different solvent systems pumped at flow rates from $1.0 \mathrm{~mL} \mathrm{~min}^{-1}$. According to the fluorescence spectra, the analytes were monitored at an excitation wavelength of $225 \mathrm{~nm}$ and an emission wavelength of $310 \mathrm{~nm}$.

By applying the optimum chromatographic conditions, resolved sharp peaks that belong to $S(-)-\mathrm{MET}$ and $R(+)$-MET were obtained at retention times of $26.16 \mathrm{~min}$ and $30.05 \mathrm{~min}$, respectively. A typical chromatogram of metoprolol enantiomers separated using the optimized chromatographic conditions is shown in Figure 2. 


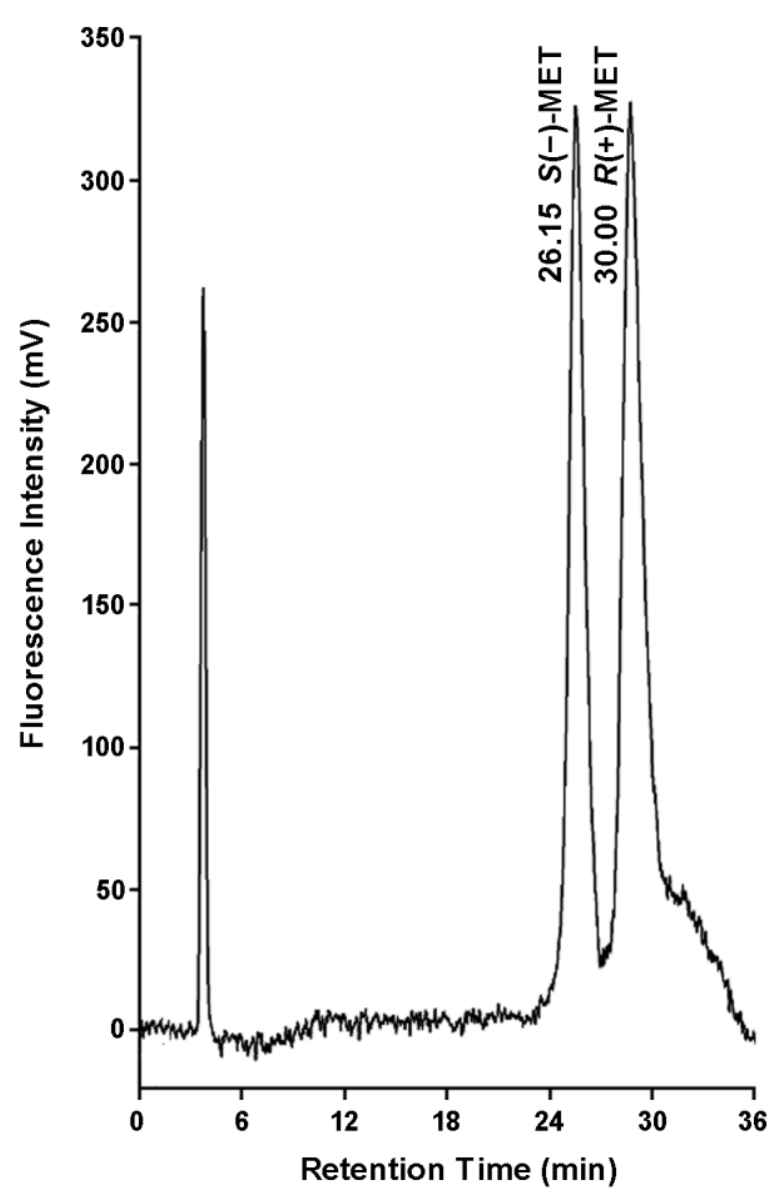

Figure 2. HPLC-FL chromatogram obtained from a standard solution containing metoprolol enantiomers at concentration of $0.75 \mu \mathrm{g} \mathrm{mL}^{-1}$.

\subsection{Method validation}

Linearity of the proposed method was done by analyzing five solutions in the range of $0.25-1.50 \mu \mathrm{g} \mathrm{mL}{ }^{-1}$ for both enantiomers. Each concentration was used in triplicate. Good linearity was observed over the above range for $S(-)$-MET and $R(+)-M E T$. The coefficients of determination obtained with linear regression of curve were 0.9953 for $S(-)$-MET and 0.9931 for $R(+)-M E T$.

The LOD and LOQ were separately determined based on the standard deviation of response of the calibration curve. The standard deviation of $y$ - intercepts of regression lines and slope of the calibration curves were used to calculate LOD and LOQ. LOD was found to be $0.06 \mu \mathrm{g} \mathrm{mL}^{-1}$ and $0.07 \mu \mathrm{g} \mathrm{mL}^{-1}$ for $S(-)-\mathrm{MET}$ and $R(+)-\mathrm{MET}$, respectively. LOQ was found to be $0.19 \mu \mathrm{g} \mathrm{mL}^{-1}$ and $0.23 \mu \mathrm{g} \mathrm{mL}^{-1}$ for $S(-)$-MET and $R(+)$-MET, respectively.

Intra- and inter-day precision and accuracy were evaluated by analyzing the QC samples at low, middle and high concentrations (Table 1). The intra- and inter-day precision was less than $4.8 \%$ and $7.0 \%$ for QC samples, respectively. The intra- and inter-day accuracies of metoprolol enantiomers were in the range from $-8.0 \%$ to $2.5 \%$ and from $-9.5 \%$ to $3.7 \%$, respectively (Table 1 ). These results suggested the results were acceptable and that the method was precise and accurate.

The recovery assessment was performed by analysing real pharmaceutical formulation samples (without metoprolol) spiked with known amounts $S(-)$-MET and $R(+)$-MET standards. The recovery of metoprolol enantiomers from tablets was higher than $80.9 \%$ with $\%$ RSD less than $8.2 \%$ for $S(-)$-MET and higher than $78.8 \%$ with $\%$ RSD less than $7.5 \%$ for $R(+)$-MET. Results from three concentrations are presented in Table 2. 
Table 1. Intra-day and inter-day precision and accuracy of the proposed HPLC-FL method.

\begin{tabular}{|c|c|c|c|c|c|c|c|}
\hline \multirow[b]{2}{*}{ Analyte } & \multirow{2}{*}{$\begin{array}{c}\text { Added } \\
\left(\mu \mathrm{g} \mathrm{mL}^{-1}\right)\end{array}$} & \multicolumn{3}{|c|}{ Intra-day } & \multicolumn{3}{|c|}{ Inter-day } \\
\hline & & $\begin{array}{c}\text { Found } \\
\left(\mu \mathrm{g} \mathrm{mL}^{-1}\right)\end{array}$ & $\begin{array}{l}\text { RSD } \\
(\%)\end{array}$ & $\begin{array}{l}\text { RE } \\
\text { (\%) }\end{array}$ & $\begin{array}{c}\text { Found } \\
\left(\mu \mathrm{g} \mathrm{mL}^{-1}\right)\end{array}$ & $\begin{array}{c}\text { RSD } \\
(\%)\end{array}$ & $\begin{array}{l}\text { RE } \\
\text { (\%) }\end{array}$ \\
\hline \multirow{3}{*}{$S(-)-M E T$} & 0.25 & 0.227 & 4.4 & -9.0 & 0.226 & 4.7 & -9.5 \\
\hline & 0.75 & 0.710 & 2.4 & -5.2 & 0.704 & 3.9 & -6.1 \\
\hline & 1.50 & 1.427 & 0.9 & -4.9 & 1.419 & 3.0 & -5.4 \\
\hline \multirow{3}{*}{$R(+)$-MET } & 0.25 & 0.244 & 4.8 & -2.5 & 0.253 & -5.0 & 1.4 \\
\hline & 0.75 & 0.761 & 3.7 & 1.4 & 0.777 & 4.4 & 3.7 \\
\hline & 1.50 & 1.538 & 1.8 & 2.5 & 1.546 & 3.1 & 3.1 \\
\hline
\end{tabular}

Table 2. Results of recovery experiments of the proposed HPLC-FL method.

\begin{tabular}{|c|c|c|c|c|}
\hline Analyte & $\begin{array}{c}\text { Added } \\
\left(\mu \mathrm{g} \mathrm{mL}^{-1}\right)\end{array}$ & $\begin{array}{c}\text { Found } \\
\left(\mu \mathrm{g} \mathrm{mL}^{-1}\right)\end{array}$ & $\begin{array}{c}\text { RSD } \\
(\%)\end{array}$ & $\begin{array}{c}\text { Recovery } \\
(\%)\end{array}$ \\
\hline \multirow{3}{*}{ S(-)-MET } & 0.25 & 0.230 & 8.23 & 92.1 \\
\cline { 2 - 5 } & 0.75 & 0.607 & 7.54 & 80.9 \\
\cline { 2 - 5 } & 1.50 & 1.312 & 2.58 & 87.5 \\
\hline \multirow{3}{*}{$\boldsymbol{R ( + ) - M E T}$} & 0.25 & 0.226 & 7.59 & 90.6 \\
\cline { 2 - 5 } & 0.75 & 0.571 & 6.87 & 78.8 \\
\cline { 2 - 5 } & 1.50 & 1.305 & 2.35 & 87.0 \\
\hline
\end{tabular}

\subsection{Application of the developed method}

The HPLC developed in the present study was used to quantify metoprolol enantiomers in tablet dosage forms. Metoprolol tablets $(50 \mathrm{mg})$ were analyzed. The average drug content was found to be $50.97 \pm 0.45 \mathrm{mg}$ of the labeled amount $(24.48 \pm 0.26 \mathrm{mg}$ for $S(-)-\mathrm{MET}$ and $26.49 \pm 0.18 \mathrm{mg}$ for $R(+)-\mathrm{MET})$. The recovery of the data and the agreement between the label claim and the amount found were good. Figure 3 shows a typical chromatogram obtained from analysis of a tablet formulation. No interfering peaks were found in the chromatogram, indicating that the tablet excipients did not interfere with the estimation of the drug by the proposed HPLC method. This confirms the suitability of the proposed method for the routine quality control determination of these components in pharmaceutical formulations. 


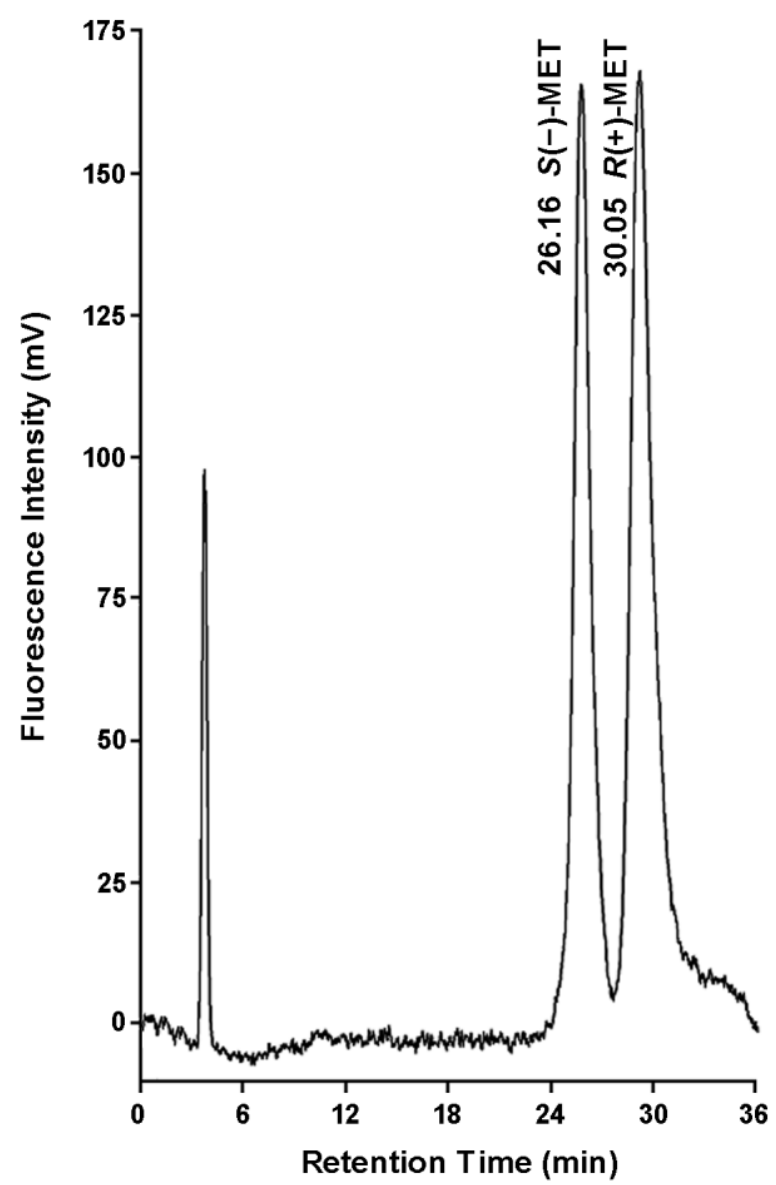

Figure 3. HPLC-FL chromatogram obtained by the analyses of commercially available tablet formulation with metoprolol.

\section{CONCLUSION}

A new HPLC method for the simultaneous determination of o $S(-)$-MET and $R(+)$-MET was developed and validated. The proposed HPLC method provides a satisfactory accuracy and precision with low limits of detection and quantification. Thus, the method is suitable for the simultaneous determination of metoprolol enantiomers in pharmaceutical formulations after a simple and rapid procedure and can be used in routine analysis in quality control laboratories.

To the best of our knowledge, for the first time these enantiomers were simultaneously determined in pharmaceutical formulations.

\section{ACKNOWLEDGMENTS}

This project was supported by funds from from the National Science Centre in the frame of the project No. N N204 355840 for 2011-2014 period, Cracow, Poland.

\section{REFERENCES}

[1] Kim K.H., Kim H.J., Kang J.S., Mar W. 2000. J. Pharm. Biomed. Anal. 22, 377-384.

[2] Lim H.K., Linh P.T., Hong C.H., Kim K.H., Kang J.S. 2001. J. Chromatogr. B 755, 259-264.

[3] Li F., Cooper S.F., Cote M. 1995. J. Chromatogr. B 668, 67-75.

[4] Lanchote V.L., Bonato P.S., Cerqueira P.M., Pereira V.A., Cesarino E.J. 2000. J. Chromatogr. B, 738, $27-37$.

[5] Cerqueira P.M., Boralli V.B., Coelho E.B., Lopes N.P., Guimarães L.F.L., Bonato P.S., Lanchote V.L. 2003. J. Chromatogr. B 783, 433-441.

[6] Mistry B., Leslie J.L., Eddington N.D. 2001. J. Chromatogr. B 758, 153-161.

[7] Morante-Zarcero S., Sierra I. 2012. J. Pharm. Biom. Anal. 62, 33-41. 
[8] Barclay V.K.H., Tyrefors N.L., Johansson I.M., Pettersson C.E. 2012. J. Chromatogr. A 1269, 208-217.

[9] Jensen B.P., Sharp C.F., Gardiner S.J., Begg E.J. 2008. J. Chromatogr. B 865, 48-54.

[10] Singh A.K., Kedor-Hackmann E.R., Santoro M.I. 2001. J. AOAC Int. 84, 1724-1729.

[11] Zhang X., Ouyang J., Baeyens W.R.G, Zhai S., Yang Y., Huang G. J. Pharm. Biomed. Anal. 31, 1047-1057.

[12] Konieczka P. 2007. Crit. Rev. Anal. Chem. 37, 173-190. 